\title{
Studying the Effect of Sales Forces' Personality Traits on the Customer Relationship Management (Isfahan Asia Insurance Company)
}

\author{
Ahmad Sedaghatnia ${ }^{1 *}$, Behnaz Rostamian ${ }^{2}$, Ali Nasr Esfahani ${ }^{3}$, Arash Shahin ${ }^{3}$ \\ ${ }^{1}$ Department of Mechanical Engineering, Isfahan University of Technology, Isfahan, Iran \\ ${ }^{2}$ Department of Management, Sheykh Bahaee University, Isfahan, Iran \\ ${ }^{3}$ Department of Management, Isfahan University, Isfahan, Iran
}

\begin{abstract}
Keywords:

Big Five Personality Traits Model, Customer

Relationship Management,

Received

17 November 2017

Received in revised form 18 May 2018

Accepted

21 May 2018

Correspondence:

Ahmadsedaghat67@yahoo. com

The purpose of this study is to examine the relationship between sales forces' personality traits and customer relationship management in Asia Insurance Company in the city of Isfahan. The statistical population of the current study includes sales forces of Asia Insurance Company in Isfahan which consists of 170 members. A sample of 120 employees was selected from this population based on the sampling table. To examine the personality traits of the sales forces in this population and measuring its dimensions, a standardized questionnaire of big five model came into use. This questionnaire was distributed among sample members and they were asked to answer the questions. To examine the validity of the questionnaire, the professors and researchers were asked to review and modify the questionnaire. The final version of the questionnaire was prepared after some modifications. Moreover, Cronbach's Alpha Coefficient was used for examining and confirming reliability of the questionnaire. In order to analyze the research data and test the research hypotheses, structural equation modeling method was used in Amos 21. The results of the study revealed that there is a significant relationship between sales forces' personality traits and customer relationship management.
\end{abstract}

(C)AIMI Journals

\section{Introduction}

Customer relationship management has been considered as one of the most important subjects for both organizational managers and academic researchers. The competition of 
increase and decrease in the customer loyalty leads the companies to use new instruments for achieving and improving customer loyalty. This can be done through customizing the customer services. Customer relationship management is an effective instrument in collecting, analyzing, and interpreting valuable customer information for managerial efforts.

The customers are considered as the main organizational capitals in today's competitive world. This is why the customer relationship management is a key factor in the organization's success. Generally, every organization's success depends on the customers' satisfaction. Customer relationship management is a process by which the management solves the customers' problems. The main concepts that are covered by customer relationship management include customer services, customer satisfaction, timely products delivery, afterpurchase services, and offering the best services for customers. The main purpose of customer relationship management is to maintain the customers and attain new ones in longterm period. This process paves a good opportunity for companies to develop their informational resources about customers. On the other hand, personality traits are one of the main research fields that have been attended by different authors and researchers. Personality refers to the model of personal characteristics that influence behavioral reactions. Different models have been presented for personality and personality traits that each of them considers certain aspects of personality. Big Five Model is one of the most important models in this area that is used by many researchers and authors. The managers attempt to manage the relations with customers. It is expected that the employees' personality influences their relations with customers. To this end, the present research determined to study the relationship between personality traits and customer relationship management.

\section{The Literature Review}

\section{Customer Relationship Management}

Because today's companies attempt to transmit their attention from products to the customers, many companies believe that having good relations with their customers can affect their profitability and income (Lin, Lyu, Hwan-Yann, \& Hsing, 2007). The concept of customer relationship management has been introduced in 1950s. Drucker (1950) pointed out that customer should be considered as the main basis of organizations. Indeed, the concept of customer relationship management was introduced in terms of seller information technologies and customer-employee relationship in the mid of 1990s. Nowadays, the successful companies seek to maintain their existing customers rather than attaining new customers. In other words, the companies use customer relationship management for increasing profitability, maintaining the existing customers, and increasing customer time value (Coltman, 2007). Achieving complete information about customers and understanding their behaviors and demands based on the environmental changes are among the most attractive characteristics of customer relationship management. In the today's competitive and unpredictable world, maintaining the existing customers is very important than attaining new customers. Moreover, the companies use customer relationship management for developing their relationship with loyal customers, motivating their repurchase intention, and maintaining their customers. The use of customer maintenance approach helps the organizations to design and develop new and effective plans for responding the customers' 
needs and decreasing their complaints. They also have to find the efficient solutions for solving their problems and analyzing their information. Indeed, these efforts can be effective and helpful in developing the relationship between customers and responding the changeable needs. It should be remembered that customer relationship management is a managerial concept that influences the process of customer attraction, maintenance, and promotion (Haq, Ramay, Rehman, \& Jam, 2010).

Ability of customer relationship management in increasing technology profitability and customer management in the ever-changing environment is the most important characteristic of customer relationship management that is attended in today's world. In actual fact, the purpose of the customer relationship management is to attain and maintain the effective and efficient customers and create suitable relations with them. Since there are different approaches in terms of customer relationship management, several definitions have been presented for the CRM (Payne \& Frow, 2006).

The use of customer relationship management has been increased in both marketing and information technology fields. From technical perspective, Chen and Pepovich (2003) refer to customer relationship management as a method that can use information technologies such as data bases and internet for making marketing communications more effective. There are several definitions of customer relationship management that concentrate on its strategic role. For example, Gray and Byun (2001) prefer the strategic role of customer relationship management to its technological role, its components, relations, and management. In addition, different authors and researchers present different definitions of customer relationship management that are related to each other. Fortunately, there is an agreement between authors in terms of classification of its components. All in all, customer relationship management consists of some parts including technology, people, commercial culture, and relations. The combination of these components is different at every level of customer relationship management (Ali \& Alshawi, 2003).

Based on Lee (2001), customer relationship management is the chain of reactions that is a new instrument of communicational strategy for conditions that informational technology is used in the higher levels for satisfying customers' needs and promoting their services quality. Every author proposes different models for customer relationship management. Wilson (1995) pointed out that the process of customer relationship management consists of three important parts. These include setting goals, selecting a team, and developing plans.

\section{Personality}

Lawrie (1974) discussed about three methods of using personality concept. According to Lawrie, personality is a concept that includes inner individual personalities and characteristics. As he pointed out, everybody has his/her own personality. For example, Senge (2006) proposed another concept for personality. He believes that personality is a persona or representative of everybody to others. The third application of personality that has been proposed by Mayo (1954) concentrates on the concept of uniqueness. He pointed out that personality is a special condition of individual and certain characteristics. Some authors pointed out that personality influences some of the organizational aspects (Haq et al., 2010). 
There are several empirical evidences that the personality traits can be grouped in five sets. These include openness, conscientiousness, extraversion, agreeableness, and neuroticism (Burke, Burgess, \& Fallon, 2006). This model is accepted and used by many authors and scholars comprehensively (Harry, 2007). Understanding the individuals' personality and behavior can be helpful for managers for creating long-term and profitable relationships with their customers. This model results in many revolutions in the personality psychology. To this end, this model developed personality traits. The use of Big Five model can be helpful in measuring openness, conscientiousness, extraversion, agreeableness, and neuroticism (Judge \& Bono, 2000). Each of these dimensions have been presented and described in the following section.

\section{Openness}

Some of the signs of openness include desire to more social relations, expressing own characteristics, and exploring others' characteristics. People who have openness trait desire for being recognized, achieving positions, controlling others, and achieving power. The people with levels of openness prefer interpersonal relations (Haq et al., 2010) and the social relations are controlled by these kind of people. They also are able to express their positive feelings than negative feelings (Berbner, 2001).

\section{Agreeableness}

People who have agreeableness trait desire to love, have amenity, honesty, integrity, help others, possess humility, and be close with others. They desire to participate in the activities that lead to maintain and reinforce humanity values and reliabilities and because they have such desirable characteristics, they prefer to go beyond their job relations with others (Jans, 1982).

\section{Consciousness}

This characteristic shows people's desire to be hardworking, have responsibility, and reliability. They prefer to participate in the environments that they can play effective role and be successful. Indeed, consciousness can be indicator of job efficiency and job satisfaction (Haq et al., 2010).

\section{Neuroticism}

This characteristic refers to desire to be anxious, sensitive, have depression, and emotional agreeableness in the people. They have not any sociology perspective and attempt to prevent from situations that need control. There is a significant relationship between neuroticism and job complexity, job efficiency, and job satisfaction (Mount \& Barrick, 1995). The characteristics such as desire to be anxious, sensitiveness, have depression, and emotional agreeableness show that they are not suitable for meetings that need long-term meeting skills, social skills, and job honesty. Therefore, they may influence relationship with customers negatively. 


\section{Openness to Experience}

This characteristic refers to the people's desire towards creativity, imagination, sensitiveness, and thoughtfulness. The people who have such characteristics show more creativity, imagination, sensitiveness, and thoughtfulness from themselves (Digman, 1990). It is rational to suppose that this people influence relationship with customers negatively.

\section{Method}

Regarding the purpose of the research, the study is a practical research and it is a correlational one considering the research methodology. Following this, the current study is a descriptive-survey research that was aimed to study the relationship between personality traits (openness, conscientiousness, extraversion, agreeableness, and neuroticism) and customer relationship management. The statistical population includes all the employees of Asia Insurance Company in the city of Isfahan. This population consists of 170 individuals and a sample of 120 employees has been selected from the population based on the sampling tables. To collect the research data, a questionnaire of Big Five personality and customer relationship management has been used. In order to examine and confirm the validity of the questionnaire, the academic professors and researchers were asked to review and modify the questionnaire. The final version of the questionnaire has been developed after modifying its draft version. Moreover, Cronbach's Alpha Coefficient has been used for examining and confirming the reliability of the questionnaire.

\section{Results}

The results of Cronbach's Alpha Coefficient are presented in Table 1. If the Cronbach's Alpha Coefficient is more than 0.70 , the reliability of the questionnaire will be acceptable.

Table 1

The Results of Cronbach's Alpha Coefficient

\begin{tabular}{lc}
\hline Variables & Cronbach's Alpha Coefficient \\
\hline Openness & 0.70 \\
Agreeableness & 0.80 \\
Neuroticism & 0.85 \\
Conscientiousness & 0.73 \\
Extraversion & 0.71 \\
Customer Relationship Management & 0.89 \\
\hline
\end{tabular}

\section{Structural Equation Modeling}

To analyze the research data and test the research hypotheses, structural equation modeling method was used in Amos 21. The independent variables include openness, agreeableness, neuroticism, conscientiousness, and extraversion. Besides, the dependent variable of this study is customer relationship management. Figure 1 displays the structural equation modeling. 


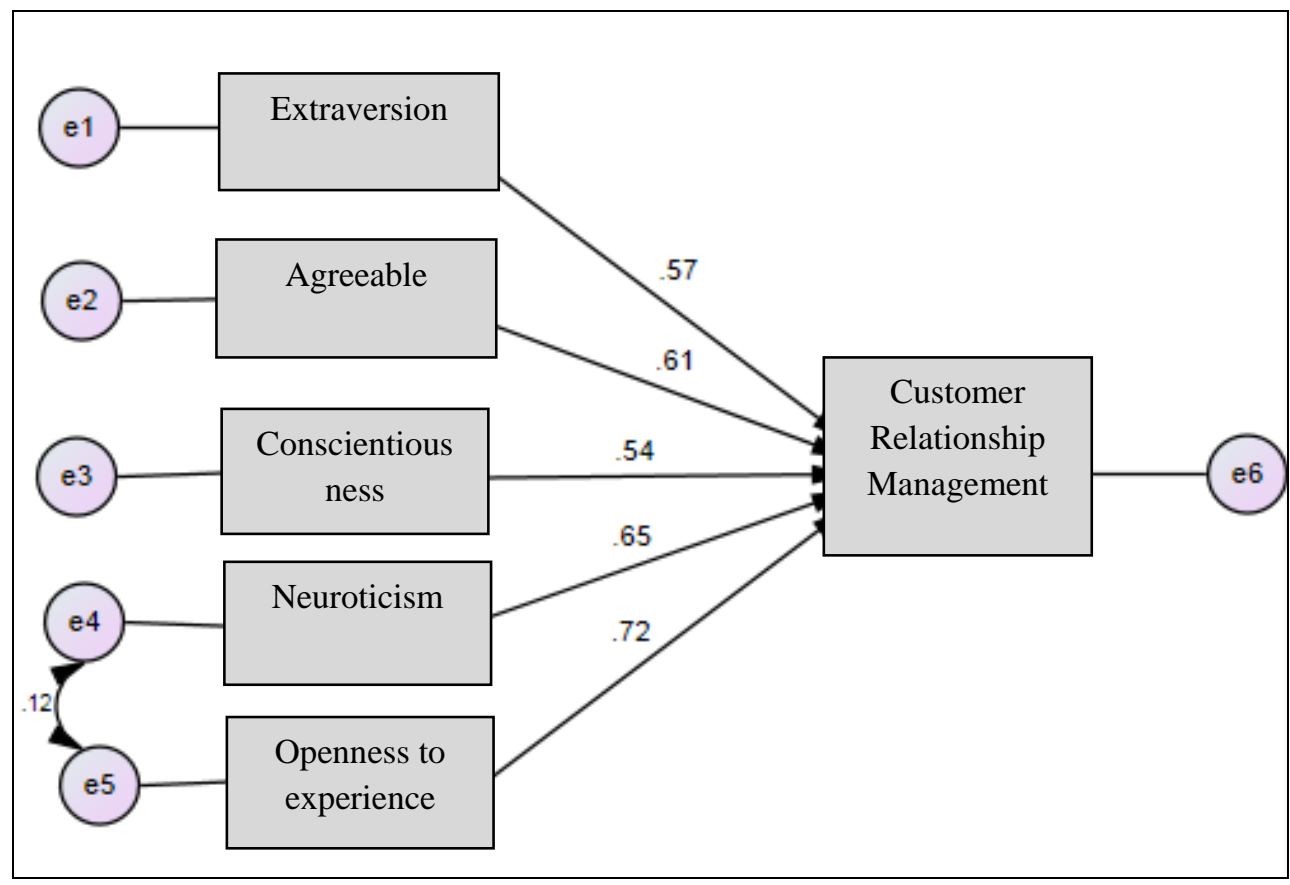

Figure 1. Structural equation modeling

To examine the fitness of the structural equation modeling, six criteria have been used and examined. The $\mathrm{df} / \mathrm{X} 2$ is the first criterion that its value should be between 1 and 3 , so that its fitness can be confirmed. This criterion is 1.65 for our model. The second criterion is RMSEA. If this criterion is close to 0.054 , its fitness will be confirmed. This value was 0.059 for our model. The GFI, IFI, NFI, and CFI are other fitness criteria that should be between 0 and 1 , so that the fitness of model can be confirmed. If these values are close to 1 , then their fitness will be confirmed significantly. These criteria were $0.92,0.93,0.90$, and 0.90 for our model that confirm its fitness. These criteria are presented in Table 2.

Table 2

The Summary of Fitness Indexes for Structural Equation Modeling

\begin{tabular}{cccccc}
\hline RMSEA & CFI & NFI & IFI & GFI & df/X2 \\
\hline 0.5 & 0.90 & 0.90 & 0.93 & 0.92 & 1.65 \\
\hline
\end{tabular}

The structural equation modeling has been used for examining the effect of independent variables (openness, agreeableness, neuroticism, conscientiousness, and extraversion) on the dependent variable (customer relationship management). The results of the data analysis that are shown in Table 3 revealed that the research independent variables influence dependent variable. The main criteria that are used for examining data and testing the hypotheses are CR and $\mathrm{P}$. If the CR is more than 1.96 and $\mathrm{P}$ is less than 0.05 , then the hypothesis will be confirmed and vice versa. As the results of Table 3 revealed, all of the research hypotheses are supported. 
Table 3

The Results of Structural Equation Modeling

\begin{tabular}{lcccc}
\hline Hypotheses & $\begin{array}{c}\text { Path } \\
\text { Coefficient }\end{array}$ & P & CR & $\begin{array}{c}\text { Hypotheses } \\
\text { Status }\end{array}$ \\
\hline Openness influences customer relationship management significantly. & 0.57 & $* * *$ & 4.65 & Supported \\
Agreeableness influences customer relationship management significantly. & 0.61 & $* * *$ & 2.98 & Supported \\
Consciousness influences customer relationship management significantly. & 0.54 & 0.12 & 3.74 & Supported \\
Openness influences customer relationship management significantly. & 0.65 & $* * *$ & 2.56 & Supported \\
Neuroticism to experience influences customer relationship management significantly. & 0.72 & $* * *$ & 5.02 & Supported \\
\hline
\end{tabular}

\section{Discussion and Conclusion}

Customer relationship management is one of the important subjects that have been attracted by both academic researchers and organizational managers. With regard to the increasingly competition between companies and the necessity of more attention to the customers' needs and wants, this subject has attracted many attentions from academic author and researchers, policy makers, and managers. Indeed, customers are the important organizational capitals that every organization's success depends on its customers' satisfaction and loyalty. With regard to the high costs of attaining new customers, maintaining the existing customers has high priority. On the other hand, it should be remembered that the employees and agents of services have direct relationship with their customers. Having a reliable and satisfactionbased relationship with customer results in their satisfaction and loyalty. This is why the managers attempt to employee professional and expert manpower in human interactions, so that they are able to influence their customers. Employees' ability to build a good relationship with customer depends on their personality. Some people have more ability in contacting with others. This is why the relationship between employees' personality traits and customer relationship management has been studied in this study. The results revealed that all of the personality traits dimensions influence customer relationship management significantly. Moreover, it is should be remembered that the effect of every independent variable on the dependent variable is different. It is suggested that the managers attempt to employ the employees that have special abilities in contacting customers and have good ability in terms of customer relationship management.

\section{References}

Ali, M., \& Alshawi, S. (2003). Investigating the impact of cross-culture on CRM implementation: A A comparative study. [online] accessed at http://www.iseing.org/emcis/EMCIS2005/pdfs/EMCIS05-Alshawi.pdf [accessed 10/12/07]

Berbner, J. (2001). Personality and stress coping. Personality \& Individual Differences, 31, 317-327.

Burke, R. J., Burgess, Z., \& Fallon, B. (2006). Workaholism among Australian Female Managers and Professionals: Job behaviors, satisfactions, and psychological health. Equal Opportunities International, 25(3), 200-213.

Chen, J. I., \& Popovich, K. (2003). Understanding customer relationship management: People, process and Technology. Business Process Management Journal, 9(5), 672-688.

Coltman, T. (2007). Why build a customer relationship management capability? Journal of Strategic Information Systems, $16,301-320$.

Digman, J. M. (1990). Personality structure: Emergence of the five-factor model. Annual Review of Psychology, 41, 417440.

Drucker, P. F. (1950). Management must manage. Harvard Business Review, 28, 80-86.

Gray, P., Byun, J. (2001). Customer Relationship Management. Center for Research on Information Technology and Organizations, University of California, Irvine 3200 Berkeley Place Irvine, Ca, 92697-4650. 
Haq, U. H., Ramay, M. I., Rehman, M. A. U., Jam, F. A. (2010). Big five personality and perceived customer relationship management. Research Journal of International Studies, 15, 37-45.

Harry, C. T. (2007). Individualism collectivism and personality. Journal of Personality, 6, 908-924.

Jans, N. A. (1982). The nature and measurement of work involvement. Journal of Occupational Psychology, 55, 57-67.

Judge, T. A., \& Bono, J. E. (2000). Five factor model of personality and transformational leadership. Journal of Applied Psychology, 85(5), 751-765.

Lawrie, R. (1974). Personality. Philosophy \& Phenomenological Research, 3, 307-330.

Lee, D. (2001) Why climb the CRM mountain? ( ${ }^{\text {nd }}$ ed.). The Customer Relationship Primer.

Lin, Y., Lyu, J., Hwan-Yann, S., \& Hsing, Y. (2007). A feasibility study of the customer relationship management application on small and medium enterprises. Journal of Scientific \& Technological Studies, 41(1), 53-63.

Mayo, B. (1954). The logic of personality. Ethics, 64(2), 144-148.

Mount, M. K., \& Barrick, M. R. (1995). The Big Five personality dimensions: implications for research and practice in human resources management. Research in Personnel \& Human Resources Management, 13, 153-200.

Payne, P., \& Frow, F. (2006). Customer relationship management: From strategy to implementation. Journal of Marketing Management, 22(1),135-168.

Senge, P. M. (2006). The fifth discipline: The art and practice of the learning organization. New York: Currency Doubleday.

Wilson, D. (1995). An integrated model of buyer-seller relationship. Journal of Academy of Marketing Science, 23(4), 335345. 